\title{
Characteristics of Cantilever Beam Fabricated by Porous Silicon Micromachining for Flow Sensor Application
}

\author{
Young-Min Kim, Chang-Taeg Seo, Duk-Soo Eun, Sung-Gen Park, Chan-Seop Jo, Jong-Hyun Lee
}

\begin{abstract}
In this paper we report the thermal stress characteristics of multiarray cantilever beam and the result of experimental researches. The cantilever beam was fabricated using porous silicon micromachining techniques, surface tension and the difference in the thermal expansion coefficients between the two films on the cantilever beam. Then the height of the curled cantilever beam is measured as a function of the annealing temperature and time. Using these results, Piezoresistive flow sensors with micro cantilever structure were fabricated using $(100), n / n^{+} / n$ three layer silicon wafer and their characteristics were then investigated. The proposed micro flow sensor consists of four identical silicon cantilever beam with piezoresistors. The total resistance and sheet resistance were obtained about $1 \mathrm{Ka}$ and $50 \mathrm{~g} /$ respectively. The results show the dependence of the sensitivity on cantilever length and geometry.
\end{abstract}

Index Terms - Cantilever Beam, porous silicon Micromachining, thermal stress, micro flow sensor

\section{INTRODUCTION}

The recent development of the microelectromechanical systems MEMS) technology and LIGA process has made it possible to fabricate three-dimensional micro size structures. The minimum size of these structures is on the order of $\mathrm{nm}$ and the maximum overall size is on the order of a $\mathrm{mm}$ [1-2]. Cantilever beams were first introduced to the nanotechnology field with their use as force sensors in atomic force microscopy (AFM)[34]. The techniques for fabricating cantilever beams have been ext ensively used, for example, various micro-sensor applications, micromechanical voltage-controlled switches and silicon micro probe cards [5-8]. This type of structure offers some additional specific features like IC process compatibility, small size, high accuracy, high reliability and low cost. In recent years, micro cantilever structures have been found to be suitable structures for silicon sensors and actuators. There are many further applications of a cantilever beam utilizing a thermal stress [9-10].

One of the most important demands of industry is the measurement of flux and speed of running fluid. Recently the demand for this has been increasing. The two main ways of measuring micro flow rate were using thermal and mechanical sensors. The mechanical sensors usually had a mechanical force sensing structure and a piezoresistance network. A mass flow rate was first converted to the deflection of the structure, and then detected by the resistance network[11]. Thus, mechanical sensors generally have a simpler fabrication process.

In this paper we have studied the use of one of these threedimensional structures, the cantilever beam, for micro flow sensing application. Firstly, cantilever beam consisting. of array of beams, having different thickness and lengths, was fabricated on a silicon substrate. The height of the curled cantilever beam was measured as a function of the annealing temperature and time. Using these results piezoresistive flow sensors with micro cantilever structure were fabricated using $(100), n / n^{+} / n$ three layer silicon wafer and their characteristics were investigated. The width and thickness of micro flow sensor were $155 \mu \mathrm{m}$ and $8 \mu \mathrm{m}$ respectively.

\section{DESIGN AND FABRICATION}

\subsection{Fabrication of silicon cantilever beam}

We were fabricated multiarray cantilever beam using porous silicon micromachining, reactive ion etching(RIE) and silicon deep-RIE technique. Fig. 1 shows a schematic diagram of silicon cantilever beam. Cantilever beams are curled up as a result of surface tension and the difference in the thermal expansion coefficients between the two films on the cantilever beam.

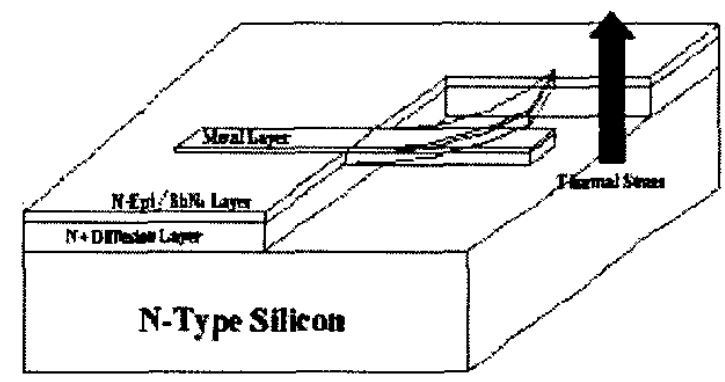

Fig. 1. Schematic diagram of silicon cantilever beam

Table 1. Process conditions of fabricated silicon wafer

\begin{tabular}{|c|c|}
\hline Process Step & Process conditions \\
\hline $\begin{array}{c}\text { (a) } \mathrm{N}^{+} \text {Diffusion } \\
\text { Layer }\end{array}$ & $\begin{array}{l}\text { 1) Wafer double side } \mathrm{POCL}_{3} \text { Deposition } \\
-1000^{\circ} \mathrm{C}, 20 \mathrm{~min} \\
\text { 2) Wafer double side UDO Deposition } \\
-430^{\circ} \mathrm{C}, \mathrm{SiH}_{4}: \mathrm{O}_{2} \\
\text { 3) } \mathrm{N}^{+} \mathrm{Diffusion} \text { Drive-in } \\
-1200^{\circ} \mathrm{C}, 16 \mathrm{hr}\end{array}$ \\
\hline (b) N EPI layer & $\begin{array}{l}\text { 1) } 100 \% \mathrm{HF} \text { remove } \rightarrow \mathrm{SC}-1 \text { cleaning } \\
\text { 2) } 1130^{\circ} \mathrm{C} \text {, Growth Rate } 1.5 \mu \mathrm{m} / \mathrm{min} \\
-\mathrm{SiHCl}_{3}, \mathrm{PH}_{3} 50 \mathrm{ppm} / \mathrm{H}_{2}, 1 \mathrm{~atm}\end{array}$ \\
\hline $\begin{array}{l}\text { (c) } \mathrm{Si}_{3} \mathrm{~N}_{4} \\
\text { Deposition }\end{array}$ & $\begin{array}{l}\text { 1) } \mathrm{SC}-2 \text { Cleaning } \\
\text { 2) Wafer double side } \mathrm{Si}_{3} \mathrm{~N}_{4} \text { Deposition } \\
-800^{\circ} \mathrm{C}, 0.5 \text { torr, } 30 \mathrm{~min} \\
-\quad \mathrm{NH}_{3}: \mathrm{SiH}_{2} \mathrm{Cl}_{2}\end{array}$ \\
\hline
\end{tabular}


Table. 1 shows details of the processes involved in the fabrication of the cantilever beam from silicon. The sheet

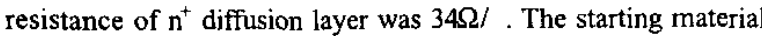
was a double-sided polished (100) n-type silicon wafer. First, the fabrication began with diffusion to make highly doped $\mathrm{n}^{+}$layer over an n-type substrate and subsequently lightly doped n epitaxial layer(Processes (a) and (b) of Table 1). The highly doped $\mathrm{n}^{+}$layer was used sacrificial layer in order to form three dimensional cantilever beams using an isotropic anodic reaction. The $\mathrm{n}^{+}$layer thickness has $20 \mu \mathrm{m}$ and the n-epitaxial layer has a thickness of $2 \mu \mathrm{m}, 5 \mu \mathrm{m}, 7 \mu \mathrm{m}$, respectively. Then a silicon nitride $\left(\mathrm{Si}_{3} \mathrm{~N}_{4}\right)$ was deposited by LPCVD on both sides of the wafer(Processes (c) of Table 1).

Fig 2. shows a flow chart for fabrication of cantilever beams The substrate for fabricating the cantilever beam was (100) silicon $n / n+n$ wafer. The silicon nitride of $1,500 \AA$ thick was deposited by LPCVD?(Fig. 2a). First, the $\mathrm{Au}(2,000 \AA) / \mathrm{Ni}$ $\mathrm{Cr}(2,000 \AA)$ were deposited on the $\mathrm{Si}_{3} \mathrm{~N}_{4}$. Further $\mathrm{Ni}-\mathrm{Cr}$ was used as a thin film to create themal stress for deflection of cantilever beam. Then aluminum was deposited by evaporation (Fig. $2 b$ ). The metal lines were patterned by photolithography. Next, cantilever beams were : patterned and deep-RIE was then performed (Fig. 2c). A porous silicon layer(PSL) was formed on an $\mathrm{n}^{+}$diffused layer by anodization. The anodic reaction was performed in aqueous $\mathrm{HF}\left(\mathrm{HF}: \mathrm{H}_{2} \mathrm{O}=3: 1\right)$ solution for $25 \mathrm{~min}$ at room temperature by applying a constant voltage of $0.7 \mathrm{~V}$ to the wafer. A current density. of $10 \mathrm{~mA} / \mathrm{cm}^{2}$ was used (Fig. $2 \mathrm{~d}$ ). The PSL was removed in a $5 \bar{w}$. $\% \mathrm{NaOH}$ solution (Fig. 2e). Since the doping concentration in the $\mathrm{n}^{+}$diffused layer is much higher than that in the n-epitaxial layer and substrate, the anodic reaction only occurs in the it diffused layer. The formation of threedimensional microstructure was controlled by the $\mathrm{n}^{+}$diffusion region and thickness of n-epitaxial layer. Finally, to obtain even more curled cantilever beams, we are performed an annealing process.

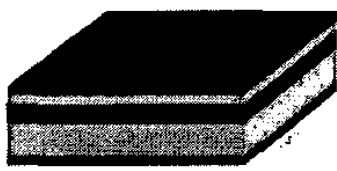

(a) $\mathrm{Si}_{3} \mathrm{~N}_{4} / \mathbf{n}^{+} \mathbf{n}^{+} / \mathbf{n}^{-n^{+}} / \mathrm{Si}_{3} \mathrm{~N}_{4}$

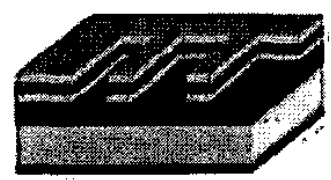

(c) Microstructure define

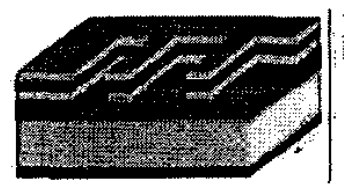

(e) PSL etching

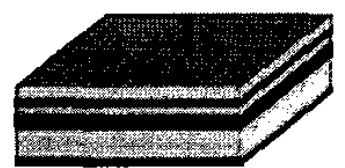

(b) Metal Deposition

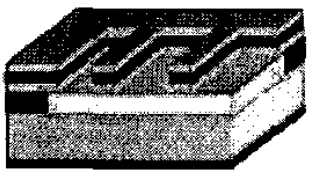

(d) PSL formation

\subsection{Fabrication of Micro Flow sensor}

Micro flow sensor structure was fabricated by unique silicon micromachining techniques using porous silicon etching and RIE process. Fig. 3 shows a structure of flow sensor composed of four silicon cantilever beams with piezoresistors.

The starting material was $(100)$-oriented $n / n+/ n$-sub silicon from which the cantilever beam was fabricated. The beam's width and length of flow sensor were $155 \mu \mathrm{m}$ and $1,050 \mu \mathrm{m}$ respectively. In the first process, the piezoresistor was pattemed by photoresist and $\mathrm{Si}_{3} \mathrm{~N}_{4}$ was etched using RIE. Piezoresistors were formed by boron diffusion. Next, the cantilever beam was etched by deep silicon RIE etcher after patterning Then aluminum was deposited as the back side ohmic contact using an evaporator to provide a uniform current density during anodization. The anodic reaction was performed in aqueous $\mathrm{HF}$ solution and removed in a $5 \mathrm{wt} . \% \mathrm{NaOH}$ solution. The anodic reaction is used multi-step process for cantilever beam of threedimensional structure. Finally, micro flow sensors were constructed by porous silicon micromachining and curled by annealing using the difference in the thermal expansion coefficient between silicon and metal.

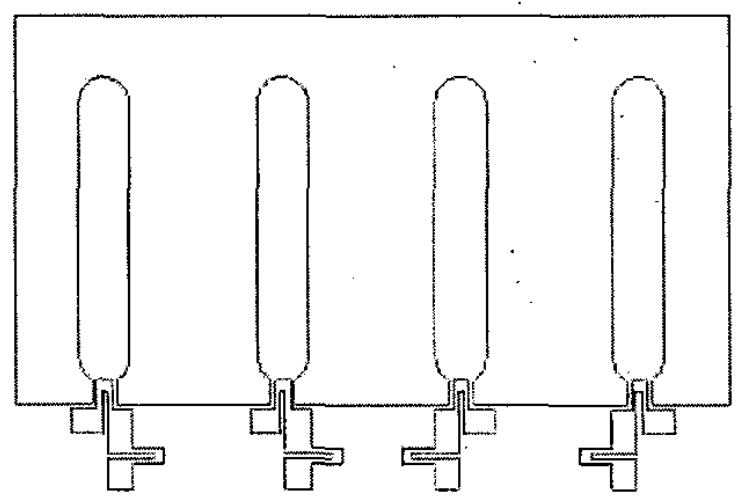

Fig. 3. Schematic diagram of flow sensor

\section{Results and Discussion}

A total of two photolithography processes were needed in the fabrication process of cantilever beam.

The condition for porous silicon formation was as shown in Table. 2. The input voltage was a constant voltage of $0.7 \mathrm{~V}$ and individual process time was $5 \mathrm{~min}$. The current of table: 2 shows measurement data of final current at individual step.

Table 2. Condition of porous silicon formation

\begin{tabular}{|c|c|c|c|c|c|}
\hline & 1step & 2step & 3step & 4step & 5step \\
\hline Voltage(V) & 0.7 & 0.7 & 0.7 & 0.7 & 0.7 \\
\hline Current(mA) & 0.9 & 0.94 & 1.10 & 1.64 & 1.99 \\
\hline
\end{tabular}

Fig. 4(a) shows SEM image of $n$ diffused layer used sacrificial layer after anodic reaction. The depth of sacrificial

Fig. 2. Fabrication process of cantilever beam 
layer was $15 \mu \mathrm{m} \sim 20 \mu \mathrm{m}$. Fig. 4 (b) shows SEM image of cantilever beam fabricated by anodic reaction. The cantilever beam was formed by anodic reaction of multi-step and shows the uniformity of multi-array cantilever beams.

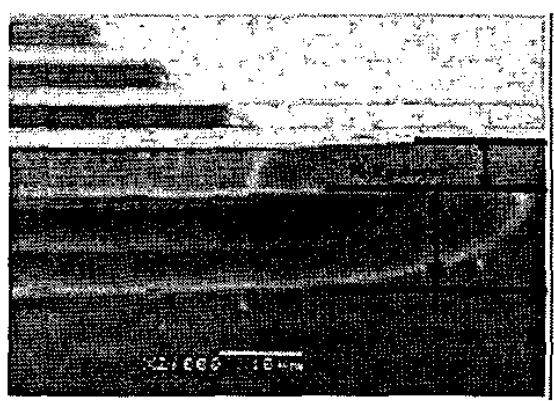

(a)

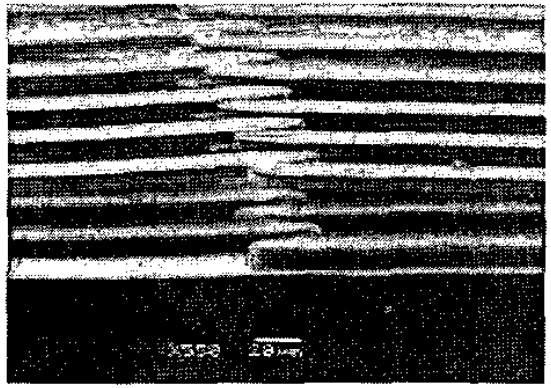

(b)

Fig. 4. SEM image of cantilever beam after anodic reaction (a) $\mathrm{N}+$ layer (b) Tip of beam

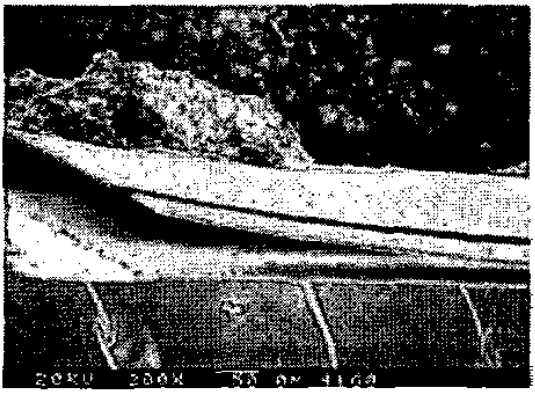

(a)

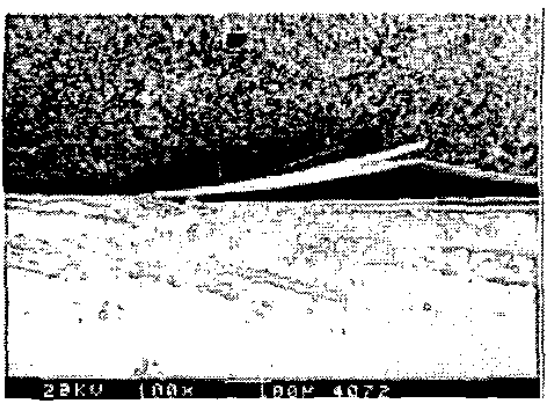

(b)

Fig. 5. SEM images of cantilever beam after annealing (a) $5 \mu \mathrm{m}$ (b) $7 \mu \mathrm{m}$
Fig. 5 shows SEM images of cantilever beam after annealing process. The basic structure is $\mathrm{Au} / \mathrm{Ni}-\mathrm{Cr} / \mathrm{Si}_{3} \mathrm{~N}_{4} / \mathrm{n}$-epi. The thickness of Au, the top metal layer, is 2,000A. The thickness of $\mathrm{Ni}-\mathrm{Cr}$ and $\mathrm{Si}_{3} \mathrm{~N}_{4}$ are $2,000 \AA$ and $1,500 \AA$ respectively. Silicon epitaxy layer thickness is $7 \mu \mathrm{m}$ [fig. 5(a)] and $\mathcal{j} \mathrm{m}[\mathrm{fig} .5(\mathrm{~b})]$ respectively. Annealing process is performed for $30 \mathrm{~min}$ at $500^{\circ} \mathrm{C}$ The width and length of cantilever beam are $40 \mu \mathrm{m}$ and $600 \mu \mathrm{m} \sim 1,000 \mu \mathrm{m}$. The cantilever beam was more curled due to the difference in the thermal expansion coefficient between the two films.

The height of the curled cantilever beam is measured as a function of the annealing temperature and time. The results of varying epitaxal layer thickness are plotted in Fig. 6 and Fig. 7. In Fig. 6, the annealing time was fixed for $30 \mathrm{~min}$. The height of beam increases linearly with decreasing silicon epitaxy layer thickness. Fig. 7 shows the height of cantilever beam annealed for $30 \mathrm{~min}$ at $500^{\circ} \mathrm{C}$. The height of beam increases linearly with increasing beam length.

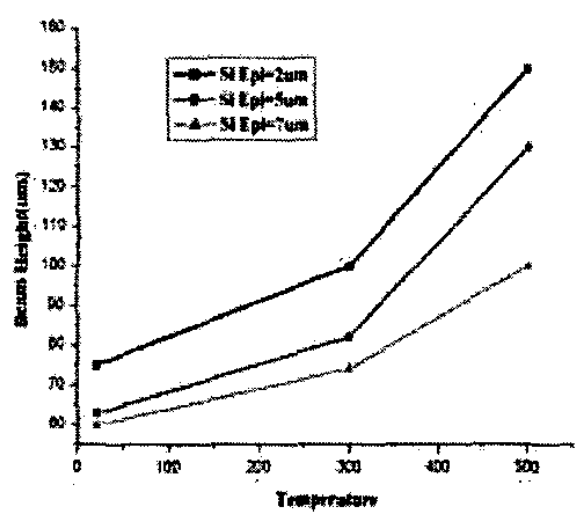

Fig. 6. Height of beam according to annealing time

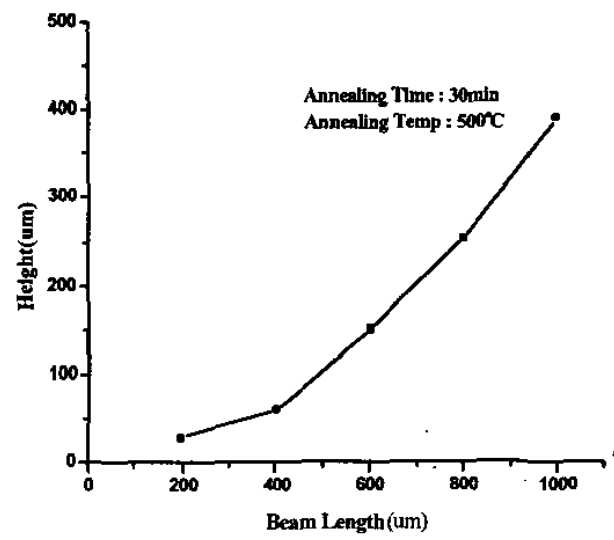

Fig. 7. Height of beam according to length variation

Fig 8. shows the basic structure of the designed flow sensor. The width and thickness of cantilever beam involved metal line are $155 \mu \mathrm{m}$ and $8 \mu \mathrm{m}$ respectively. The length of cantilever is $1050 \mu \mathrm{m}$. One of flow sensors composed of silicon cantilever beam and piezoresistors for flow detection.

Fig. 9 shows SEM image of fabricated micro flow sensor. The 
sensor was fabricated by porous silicon etching process using anodic reaction and annealing process using thermal expansion coefficient between the two films. The sensor was loaded on the inner surface of a tube and tested by varying $\mathrm{N}_{2}$ gas flow rate from 0 to $20 \mathrm{NL} / \mathrm{M}$ (normal liter per minute). A wheastone bridge was formed with two piezoresistors and two fixed resistors and its output voltage was amplified 1000 times using differential amplifier. Fig. 10 shows the output voltage vs. flow rate relation of cantilever beam. The output voltage increases linearly with increasing flow rate.

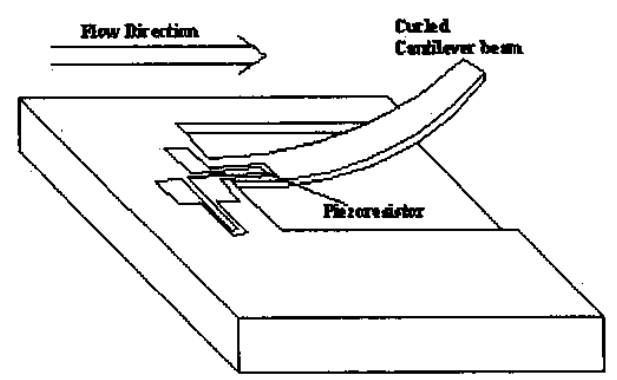

Fig 8. The basic structure of micro flow sensor

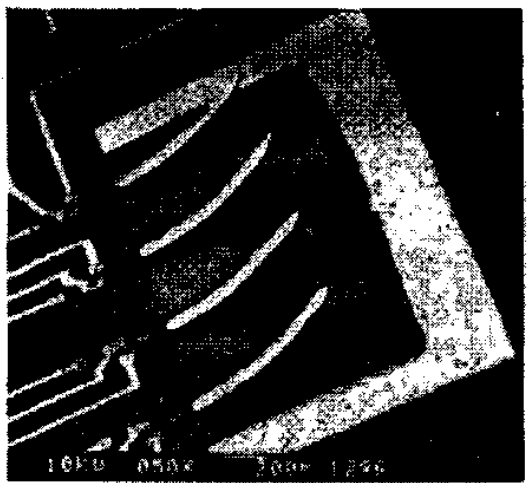

Fig 9. SEM photograph of the micro flow sensor

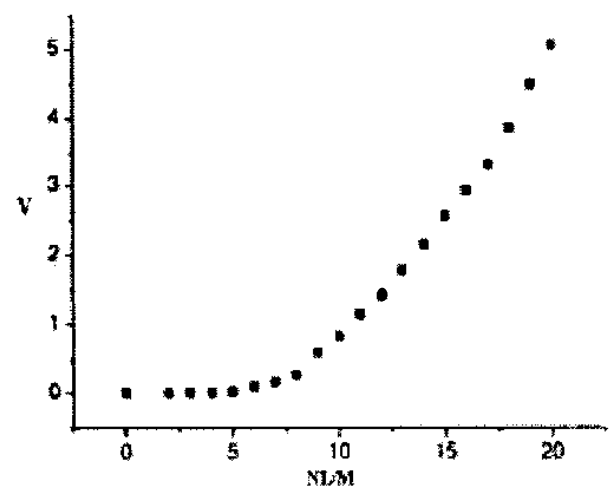

Fig 10. Output voltage vs. $\mathrm{N}_{2}$ flow rate

\section{Conclusion}

In this paper, we have fabricated multi-array cantilever beam using anodic reaction, RIE and silicon deep-RIE process. In order to make porous silicon, anodic reaction process was used five- step. The cantilever beam was performed annealing process to measure the height of curled cantilever beam according to temperature and time variety. The height of beam increased linearly with decreasing silicon epitaxial layer thickness and increasing beam length. The results show that the curvature of cantilever beam depends on the difference in the thermal expansion coefficient between the two films. Using these results we fabricated a micro flow sensor. Fabrication process of this sensor is much simpler and less expensive compared to other flow sensor. The total resistance and sheet resistance obtained were about $1 \mathrm{~K} \Omega$ and $50 \Omega /$ respectively. The output voltage increases linearly with increasing flow rate. The results show the dependence of the sensitivity on cantilever length and geometry.

\section{References}

[1] M. T. A. Saif, N. C. MacDonald, "Planarity of large MEMS," IEEE J. Microelectromech. Sys., vol. 5, pp. 79-97, 1996.

[2] W. C. Tang, T. H. Nguyen, and R. T. Howe, "Laterally driven polysilicon resonant microstructures," Sens. Actuators, vol. 20, pp.25-32, 1989.

[3] G.Binning, C. F. Quate, and Ch. Gerber,"Atomic force microscope," Phys. Rev. Lett., vol. 56, pp.930-933, Mar. 1986.

[4] A. Gupta, J. P. Denton, H. McNally, R. Bashir, "Novel fabrication method for surface micromachined thin singlecrystal silcon cantilever beams," IEEE J. Microelectromech. Syst., Vol. 12, pp. 185-192, 2003

[5] R. Muller, I. Pavelescu, V. M. Poladian, E. Manea, O. T. Nedelcu, V. Avramescu, "3D Microstructured cantilevers for optical detection applications," in CAS '97 Proc. IEEE Semiconductor Conference, vol. 2, pp.537-540, 1997

[6] K. Kischer, J. Muller, R. Hoffmann, F. Wasse, D. Salle, "Elastooptical properties of SiON layers in an integrated optical interferometer used as a pressure sensor," IEEE J. Lightwave technology, Vol. 12, pp. 163-1169, 1994

[7] P. A. Rasmussen, J. Thaysen, S. Bouwstra, A. Boisen, "Modular design of AFM probe with sputtered silicon tip," Sens. Actuators, 83(2001), pp. 96-101

[8] N. Funukawa, K. Ohnishi, "A structure of angular accereleration sensor using silicon cantilevered beam with piezoresistors," in the 1992 International Conference Proc., Industrial Electronics, Control, Instrumentation, and Automation IEEE, vol.3, pp. 1524-1529, 1992

[9] V. M. Poladian, R. Muller, N. Mierlacioiu, "Modelling residual stress in a multiplayer micromachined cantilever," in CAS 2000 Proc. IEEE Semiconductor Conf., vol.2 pp. 499-502, 2000

[10] Y. Zhang, Y. Whzng, R. B. Marcus, "Thermally actuated microprobes for a new wafer probe card," IEEE $J$. Microelectromech. Syst., vol. 8, pp. 43-49, 1999

[11] B. W. Chui, T. D. Stowe, Y. S. Ju, K. E. Goodson, T. W Kenny, J. Mamin, B. D. Terris, R. P. Ried, D. Rugar, "Low-stiffness silicon cantilevers with integrated heaters and piezoresistive sensors for high-density AFM thermomechanical data storage," IEEE J. Microelectromech. Syst., vol. 7, pp. 69-78, 1998 


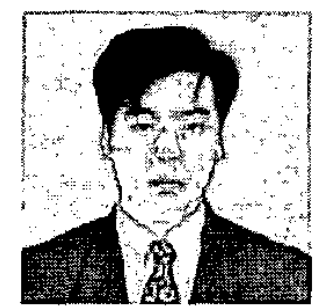

Young-Min Kim was born in Korea 1966. He received the B.S. and M.S. degree in electronic engineering from Cheju National University, Cheju in 1990 and 1998, respectively. $\mathrm{He}$ candidates the Ph.D. in electronic engineering from Kyoungpook National University, Daegu, Korea. in 1999 and 2003.

His research interests are in microelectromechanical system (MEMS)-based RF passive device, silicon probe card, microsensor and MEMS fabrication process.

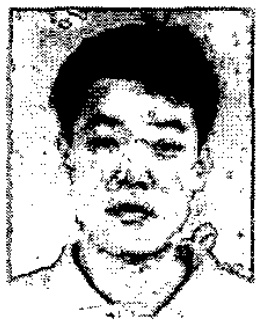

Chang-Taeg Seo was born in Korea in 1975. He received the B.S. and M.S. degree in electronic engineering from Kyungpook National University, Daegu in 1997 and 1999, respectively. He candidates the Ph.D. in electronic engineering from Kyoungpook National University, Daegu, Korea. in 1999 and 2003.

His research interests are microsensor, microelectromechanical system(MEMS) applications and technology, microfluidics and MEMS fabrication process.

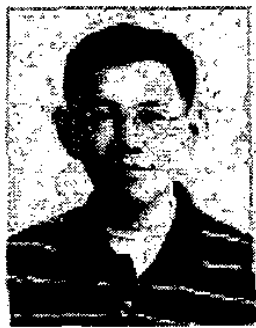

Duk-Soo Eun was born in Korea in 1978. He received the B.S degree in physics from Keimyung University and the M.S degree in Sensor engineering from Kyoungpook National University, Daegu, Korea in 2001 and 2003 . He candidates the $\mathrm{Ph} . \mathrm{D}$ in electronic engineering from Kyoungpook National University, Daegu, Korea.

His research interests are focused on coaxial cable and cpw and silicon epitaxy by chemical vapor deposition

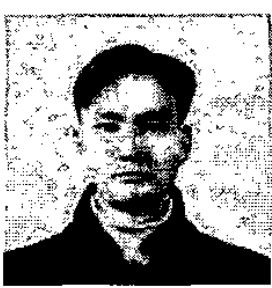

Sung-Gen Park was born in Korea in 1975. he received the B.S. degree in Electronic Engineering from Dongseo University in Pusan in 2001.

His current research interest is coplanar waveguide(CPW) and digital radiography(DR) using MEMS(Micro Electro Mechanical System) technology.

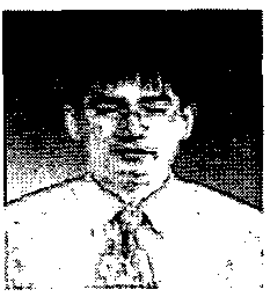

Chan-Seop Jo was born in Korea in 1965. He received the B.S., M.S. and $\mathrm{Ph} . \mathrm{D}$. degrees in electronic engineering from Kyungpook National University, Daegu, Korea, in 1988, 1990 and 1994, respectively. His doctorial research concerned the application of silicon micromachining using porous silicon and the fabrication of silicon acceleeometers. Currently he is an associate professor at the School of Electronic and Electrical Engineering at Sangju
National University. His current research interests include microsensor and microelectromechanical system applicon.

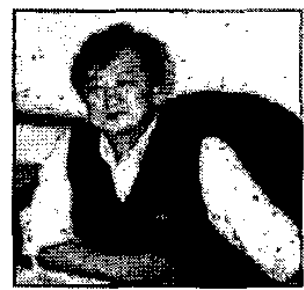

Jong-Hyun Lee was born in Korea in 1949. He attended Kyungpook National University (KNU) where he received the Bachelor and the Master of Engineering in Electronics in 1972,1976 , respectively. He was awarded his Docteur d'Ingenieur in electronics from ENSERG-INP, Grenoble, France, in 1981. He joined the School of Electronic \& Electrical Engineering at KNU, in 1982, where he taught courses in semiconductor physics, electronic devices, integrated circuits fabrication process, and electronic materials. Between 1994 and 1997, he has served as director of the school, and he is now professor. From 1985 to 1986, he was employed at ENSERG-INP, in France, as a professeur associe. where he participated in research on $\mathrm{SOI}$ (Silicon-On-Insulator). $\mathrm{He}$ is now actively engaged in research on semiconductor sensors, micro-machined devices, nano-structures, and their applications. 